\section{Кириллова О.Ю.}

канд. экон. наук, доцент, профрессор кафедры экономики, АНО ВО «Институт международных экономических связей», Москва

e-mail: cg_123@mail.ru

Kirillova O.Yu.

Candidate of Economic Sciences, Associate Professor, Professor at the Department of Economics, Institute of International Economic Relations, Moscow

e-mail: cg_123@mail.ru

\section{Проблематика, задачи и перспективы развития обучения в области корпоративного управления в высшей школе РФ}

\begin{abstract}
Аннотация
Рассматривается проблематика систем управления образовательными организациями в сфрере высшего образования. На примере основной образовательной программы - Корпоративное управление - показана взаимосвязь компетенций, приобретаемых в процессе обучения, образовательных траекторий и трудовых функций профессиональных стандартов, лежащих в основе подготовки в данной предметной области.
\end{abstract}

\section{Ключевые слова:}

корпоративное управление, основная образовательная программа, компетенции обучающегося, профессиональные стандарты, реструктуризация системы управления вузом.

\section{Problematics, Tasks and Prospects of Education Development in the Corporate Governance Area in the Russian High School}

\begin{abstract}
This article discusses the problematic of educational institutions management systems in higher education On example of the main educational program - Corporate Governance - the author shows the competencies relationship acquired during training, educational paths and work functions of professional standards underpinning training in a given subject area.

Keywords:

corporate governance, main educational program, learner competence, professional standards, restructuring of university management system.
\end{abstract}

Высшая школа переживает структурную перестройку, сопровождающуюся фазой сжатия в сфере экономико-управленческого образования. С одной стороны, объективная основа происходящего - несоответствие спектра подготовки выпускников образовательных организаций реальным потребностям компаний в современной российской бизнес-среде. С другой - образовательные организации, в том числе и вузы, должны становиться активными членами гражданского общества, быть тесно интегрированными в окружающий социум, что, в свою очередь, невозможно вне отношений института корпоративного управления. Таким образом, возникает два направления развития корпоративности образовательных организаций - внешнее и внутреннее.

Развитие российского предпринимательства в инновационной экономике корпоративного типа требует качественно новых подходов к организации обучения. Внешний аспект развития вуза в рамках института корпоративного управления связан с такими направлениями деятельности, как корпоративная социальная ответственность, формирование гражданской позиции, благотворительность, волонтерство, взаимодействие с заинтересованными лицами и рядом других. Очевидно, что они могут быть решены только на основе качественной профессиональной подготовки выпускника.

Переход к трехуровневой системе образования обозначил необходимость преемственности образовательных программ для эффективного формирования профессиональных качеств будущего бакалавра, магистра и научного сотрудника. Со стороны рынка труда этот «коридор» задан профессиональными стандартами в соответствующей области. Тенденции упрощения государственных требований к составу и содержанию образовательных программ не добавляют ясности их разработчикам. Главными ориентирами становятся востребованность выпускника на рынке и оценка работодателя. Границы 
направлений подготовки размываются, так как переход от бакалавриата к магистратуре может сопровождаться «зигзагами» образовательной траектории. При этом возможны как взаимодополняющие друг друга комбинации образовательных программ разных уровней (например, бакалавриат - «Менеджмент», магистратура - «Юриспруденция»), так и плохо сочетаемые. С одной стороны, обучающемуся предоставлена возможность смены направления подготовки в случае «непопадания в себя», с другой - отдельно взятая ступень образования не дает полной профессиональной доводки.

Современная образовательная среда предполагает создание таких условий, которые позволяют уже в процессе обучения применить полученные теоретические знания на практике и сформировать компетенции, необходимые в профессиональной деятельности. Это становится возможным благодаря тесному сотрудничеству образовательных программ с компаниямиработодателями, организации практик в структурных подразделениях, на реализацию функций которых направлена подготовка специалистов соответствующего профиля. К сожалению, до сих пор в большинстве образовательных организаций сохраняется ситуация, при которой ООП построена не по принципу «как лучше», а исходя из того «что можем». В основе этого лежит ряд объективных причин.

Во-первых, разработчиками программ бакалавриата и магистратуры выступили выпускающие кафедры. Вроде бы все логично - была выпускающая кафедра - стала выпускающая программа. Но функции кафедры при этом никто не отменял, а обязанностей по ООП добавилось ровно столько же: начиная от организации набора и рекламной компании, кончая взаимодействием со всеми заинтересованными в реализации этой программы сторонами: потенциальными абитуриентами, их родителями, профильными для соответствующего направления подготовки компаниями (их представителями из служб HR), различными структурами по трудоустройству, членами приемных комиссий и другими, в терминах теории корпоративного управления объединяемыми понятием «стейкхолдеры». При этом резкое расширение обязанностей профессорско-преподавательского состава кафедр совершенно не имеет мотивационной поддержки и ресурсного обеспечения и не вызывает энтузиазма.

Отсутствие сбалансированности полномочий и ответственности, функциональной нагрузки и адекватного стимулирования - вторая важная причина снижения качества подготовки в вузах. В процессе коммерциализации образовательных услуг кафедры (в лице заведующих) были «назначены» предприни- мателями. Но требования рынка и госрегулятора в отношении контроля деятельности образовательной организации и качества образования в рамках ООП растут, а ресурсов у кафедр не прибавляется. Можно возразить, что появились финансовые средства от коммерческих наборов, но их достаточность, скорее, исключение, чем правило. В большинстве случаев их хватает на то, чтобы удержаться «на плаву».

Для эффективного формирования профессиональных качеств большое значение имеет преемственность образовательных программ различных уровней. Вместе с тем в настоящее время наблюдаются существенный разрыв в преемственности образовательных программ, их ориентации на рынок труда и на конкретных работодателей. На рубеже массового выхода первой волны бакалавриата далеко не все образовательные организации смогли предложить качественное продолжение образования в магистратуре, соответствующее требованиям работодателя. При этом очевидно, что количество направлений подготовки на уровне бакалавриата должно снижаться, они должны быть простыми, понятными для выбора абитуриента, а магистратура, напротив, должна предоставлять диверсифицированный спектр программ в рамках каждого направления, перечень которых соответствует региональным потребностям рынка труда.

Корни этой проблемы уходят в то время, когда планы специалитета делились между бакалавриатом и магистратурой. Перестройка системы подготовки «сверху» без соответствующей реструктуризации системы управления вузом в длительном (не менее 5 лет) режиме частого внесения изменений в нормативно-методическую документацию привела к невосприимчивости исполнителей как на уровне отдельных структурных подразделений, так и на уровне образовательных организаций. Можно поделиться наблюдением автора: на уровне московского образовательного пространства наиболее востребованные кадры ППС ушли в вузы с сильным менеджментом, т.е. предпочли профессиональную составляюшую развития, отказавшись от навязанных функций по администрированию ООП. При этом необходимо отметить полное отсутствие предложений со стороны госрегулятора в лице Министерства образования и науки РФ по изменениям в системах управления вузов, даже на уровне рекомендаций.

Подытоживая изложенное можно отметить, что для эффективной работы вузу в зоне ближайшего стратегического развития необходимо следующее:

- Интегрироваться в гражданское общество, приняв за основу деятельности принципы корпоративного управления. 
- Реструктурировать систему управления таким образом, чтобы соответствовать требованиям окружающего социума, госрегулятора, рынка образовательных услуг и работодателя.

- Обеспечить преемственность основных образовательных программ в трехуровневой системе подготовки.

Ведущую роль в решении обозначенных задач играет развитие взаимодействия с ключевыми участниками образовательного процесса, прежде всего с работодателями, которое начинается с осознания разработчиками того, какие трудовые функции способен осуществлять выпускник конкретной ООП. В качестве примера можно рассмотреть магистерскую программу «Корпоративное управление», которая в июне 2016 г. была аккредитована в Национальном центре сертификации управляющих (НЦСУ) при участии членов кафедры корпоративного управления ФГБОУ ВО «Государственный университет управления».

Потребность в профессиональном осуществлении функций и процедур корпоративного управления обусловлена, с одной стороны, экономическом курсом на корпоратизацию в рамках цивилистической доктрины развития. В реалиях бизнеса это означает соблюдение баланса интересов заинтересованных сторон, учет кросс-культурных различий, социально ответственное поведение, нацеленность на взаимодействие с государством, активный диалог с ним и т.д. С другой - возрастающей ролью государства как собственника, акционера и участника корпоративных отношений, следовательно, - представительства государственных интересов в органах корпоративного управления компаний.

Отметим, что выведение на рынок такого продукта, как основная образовательная программа ООП, нацеленная на подготовку магистров по корпоративному управлению, имеет ряд проблем, например, не пришедший к завершению спор в научной и деловой среде, кем должен быть корпоративщик в базовом образовании - экономистом, юристом или управленцем, а также несформированность потребности в практике корпоративного управления в профессионально подготовленных исполнителях соответствующих функций и процедур.

ООП «Корпоративное управление» реализуется на уровне магистратуры в объеме 120 часов на протяжении 24 месяцев на базе образовательного стандарта направления 38.04.02 «Менеджмент». Цель (миссия) образовательной программы «Корпоративное управление» - развитие у студентов личностных качеств, формирование общекультурных, общепрофессиональных и профессиональных ком- петенций в области осуществления функций систем корпоративного управления компаний различных организационно-правовых форм и сфер деятельности, занимающих активную гражданскую позицию, ведущих свою деятельность на основе баланса интересов всех участников, демонстрирующих социально ответственное поведение и нацеленных на непрерывное профессиональное совершенствование своих компетенций.

Состав и объем компетенций, формируемых в ходе освоения данной ООП, позволяет магистрам занимать должности специалистов, экспертов, помощников первых лиц и пр. В структурных подразделениях компаний, реализующих функции корпоративного управления.

В бизнес-среде профессиональными преломлениями выпускника ООП «Корпоративное управление» могут быть такие, как представитель собственника, управляющий государственным пакетом акций, член совета директоров, член ревизионной комиссии, инвестор и пр.

Карьерный рост на базе подготовки в рамках данной ООП может иметь различные функциональные направления: стратегическое, финансовое, внутреннего контроля и другие, а также развитие квалификаций 8 и 9 уровней профессиональных стандартов соответствующих направлений, предполагающих руководство структурными подразделениями и организацией в целом.

На рис. 1 отражены состав компетенций, приобретенных обучающимся в итоге освоения данной ООП, а также их трансформация в трудовые функции профессиональных стандартов соответственно выделенным образовательным траекториям.

Помимо упомянутых образовательных траекторий, на рынке труда растет интерес к специалистам по нефинансовой отчетности. Вызван он необходимостью раскрытия публичными компаниями информации об успешности ведения бизнеса, причем не только с финансовой и нормативной точек зрения.

Российские стандарты не содержат трудовой функции, характеризующей данный вид деятельности, который регламентирован международными стандартами, к основным из которых относятся:

- Стандарт AА1000, регламентирующий отчетность в области устойчивого развития организаций (разработан Институтом социальной и этической отчетности (Institute of Social and Ethical Accountability) в 2009 г.);

- Руководство по отчетности в области устойчивого развития (GRI);

- Стандарт «Саншайн» по составлению корпоративных отчетов для заинтересованных сторон; 


\section{Входные компетенции Ооп «Корпоративное управление»}

Желающие освоить программу подготовки магистра по ООП «Корпоративное управление» должны иметь высшее профессиональное образование, подтвержденное документом государственного образца, и владеть знаниями на уровне не ниже бакалавра по специальности «Менеджмент»:

- знать основные категории экономической науки, владеть методами анализа экономических и социальных процессов;

- знать основные функции менеджмента, понимать законы функционирования организаций;

- владеть навыками делового этикета, коммуникаций, принятия управленческих решений, управления консрликтами;

- иметь представление об управленческой деятельности в организациях различных фрорм собственности

Наиболее рациональными в плане профессионального роста в области компетенций программы «Корпоративное управление»

являются программы бакалавриата направлений «Экономика», «Менеджмент», «Юриспруденция». Возможны и другие направления бакалавриата

Профессиональные компетенции ООП «Корпоративное управление»

(на базе ОС направления «Менеджмент»)

- способность участвовать в разработке корпоративной стратегии;

- способность проводить корпоративную реструктуризацию;

- способность осуществлять корпоративные процедуры;

- способность управлять балансом интересов лиц, заинтересованных в деятельности организации;

- способность составлять несинансовую отчетность;

- способность осуществлять функции системы внутреннего контроля

ОБРАЗОВАТЕЛЬНЫЕ ТРАЕКТОРИИ ООП “Корпоративное управление»

\begin{tabular}{|l|l||l|l|}
\hline \multicolumn{1}{|c|}{} & \multicolumn{1}{|c|}{} & \\
\hline $\begin{array}{l}\text { Специалист по стратегическому } \\
\text { управлению }\end{array}$ & $\begin{array}{l}\text { Специалист по внутреннему } \\
\text { контролю }\end{array}$ & $\begin{array}{l}\text { Специалист по корпоратив- } \\
\text { ному взаимодействию/ } \\
\text { Корпоративный секретарь }\end{array}$ & $\begin{array}{l}\text { Специалист по корпоративным } \\
\text { контам }\end{array}$ \\
\hline
\end{tabular}

ТРУДОВЫЕ ФУНКЦИИ

в соответствии с профессиональными стандартами, лежащими в основе подготовки

І. Управление (руководство) организацией,

разработанный Национальным центром сертификации управляющих в 2010 г. С изменениями 2016 г.

8 A.4:

Выявлять интересы акционеров

(владельцев) и определять

стратегические цели и приорите-

ты развития организации

\section{C.2:}

Определять политику мотивации и вознаграждения исполни-

тельного руководства организации

8 D.1:

Проявлять высокий уровень личностной эффективности, умений межличностного взаимодействия

\section{D.3:}

Задавать собственным примером высокий уровень требований к добросовестному и честному исполнению своих обязанностей в организации

\begin{tabular}{|l|l|l|}
\hline & & $\begin{array}{l}\text { 8 Е.1: } \\
\text { Обеспечивать защиту прав и равное отношение ко всем акционе- } \\
\text { рам (владельцам) }\end{array}$ \\
\hline & $\begin{array}{l}\text { 8 Е.2: } \\
\text { Учитывать интересы стейкхолдеров и требования к корпоративной } \\
\text { социальной ответственнсти }\end{array}$ \\
\hline
\end{tabular}

7 A.3:

Разрабатывать общую стратегию организации

7 B.4:

Разрабатывать организационную структуру, частные политики и процедуры, участвовать в корпоративном управлении

7 C.1:

Организовать команду менеджеров высшего звена управления

7 C.2:

Координировать деятельность членов команды менеджеров высшего звена управления
8 A.2:

Участвовать в разрешении конфрликтов акционеров. Осуществлять медиаторство в спорных или конфрликтных ситуациях

8 A.4:

Выявлять интересы акционеров (владельцев) и определять стратегические цели и приоритеты развития организации 


\begin{tabular}{|l|l|l|l|}
\hline $\begin{array}{l}7 \text { Е.1: } \\
\text { Оценивать проведение измене- } \\
\text { ний в организации и во внешней } \\
\text { среде }\end{array}$ & & & \\
\hline $\begin{array}{l}\text { Е.3: } \\
\text { Определять необходимость и } \\
\text { возможность изменений } \\
\text { в организации }\end{array}$ & & & \\
\hline
\end{tabular}

II. Специалист по финансовому консультированию, утвержденный приказом Министерства труда и социальной защиты России от 19 марта 2015 г. № 167н (зарегистрировано в Минюсте России 9 апреля 2015 г. № 36805)

\section{$\mathrm{A} / 01.6$}

Мониторинг конъюнктуры рынка

банковских услуг, рынка ценных

бумаг, иностранной валюты,

товарно-сырьевых рынков

III. Специалист по внутреннему контролю (внутренний контролер), утвержденный приказом Министерства труда и социальной защиты РФ от 22 апреля 2015 г. № 236н

\begin{tabular}{|l|l|l|l|}
\hline & $\begin{array}{l}\text { 6-7 уровень } \\
\text { Руководство структурным/ } \\
\text { самостоятельным специаль- } \\
\text { ным подразделением } \\
\text { внутреннего контроля }\end{array}$ & & \\
\hline & 8 уровень & & \\
Организация и контроль & & & \\
текущей деятельности & & & \\
системы внутеннего & & & \\
контроля экономического & субъекта & & \\
\hline
\end{tabular}

IV. Специалист в области медиации (медиатор), утвержденный приказом Министерства труда и социальной защиты Российской Федерации от 15 декабря 2014 г. № $1041 \mathrm{H}$

\section{6 уровень}

Ведение процедуры медиации (без специализации)

А/01.6 Организационно-техническое и документарное обеспечение процедуры медиации

A/02.6 Подготовка к процедуре медиации

A/03.6 Ведение процесса выработки, согласования условий медиативного соглашения и завершения процедуры медиации

\begin{tabular}{|l|l|l|}
\hline & & $\begin{array}{l}7 \text { уровень } \\
\text { Ведение процедуры медиации в специализированной сфере }\end{array}$ \\
\hline & & $\begin{array}{l}\text { 8 уровень } \\
\text { Супервизия в специализированной сфере медиации }\end{array}$ \\
\hline
\end{tabular}

V. Специалист по управлению рисками, утвержденный приказом Министерства труда и социальной защиты Российской Федерации от 7 сентября 2015 г. № 591н

\section{6 уровень}

Разработка отдельных направлений риск-менеджмента

\begin{tabular}{|l|l|l|l|}
\hline & $\begin{array}{l}\text { 7В } \\
\text { Обеспечение эффрективной } \\
\text { работы системы управления } \\
\text { рисками }\end{array}$ & & \\
\hline $\begin{array}{l}\text { МСтодическая разработка, поддержание и координация процесса } \\
\text { управления рисками }\end{array}$ & & \\
\hline & $\begin{array}{l}\text { 8D } \\
\text { Построение и контроль } \\
\text { процесса управления } \\
\text { рисками }\end{array}$ & & \\
\hline $\begin{array}{l}\text { 8Е } \\
\text { Стратегическое корпоративное управление рисками }\end{array}$ & & \\
\hline
\end{tabular}

Рис. 1. Распределение трудовых функций профессиональных стандартов по образовательным траекториям ООП «Корпоративное управление» 
- Принципы Экватора, содержащие требования к отчету по социальной и экологической ответственности, разработанные Организацией «Принципы Экватора финансовых учреждений» (Equator Principles Financial Institution - EPFI) в 2006 г.

Стремление корпораций повысить устойчивость и конкурентоспособность на рынке с помощью предоставления нефинансовых отчетов имеет устойчивую тенденцию к росту, так как в них отражаются составляющие социально-ответственного поведения в бизнес-среде и окружающем социуме.
С момента своего становления корпорации прошли более чем полуторавековую историю развития и превратились в доминирующую международную форму экономической организации. В российской бизнес-среде внедрены и продолжают развиваться принципы корпоративного управления, выступающие основой поддержания благоприятного инвестиционного климата. В связи с этим перед системой высшего образования стоит важная задача - прогнозирование потребности кадров требуемой квалификации в среднесрочном периоде развития для обеспечения возможности работать на опережение запросов экономической практики.

\section{Литература}

1. Кириллова О.Ю. Регуляторный риск в управлении основной образовательной программой в системе высшего образования [Текст] / О.Ю. Кириллова // Качество образования. 2015. № 1-2 (январь - февраль).С. $48-53$.

\section{References}

1. Kirillova O.Yu. Regulyatornyy risk v upravlenii osnovnoy obrazovatel'noy programmoy v sisteme vysshego obrazovaniya [Regulatory risk in the management of the basic educational program in higher education]. Kachestvo obrazovaniya [Quality of education]. 2015, I. 1-2 (January-February), pp. 48-53. 